\title{
Predictors of nurses considering leaving the profession due to work-related stress in a large pediatric and women's hospital in the United States
}

\author{
Joseph Hagan*1, Lynda Tyer-Viola², Krisanne Graves ${ }^{2}$ \\ ${ }^{1}$ Newborn Center, Texas Children's Hospital, United States \\ ${ }^{2}$ Nursing Department, Texas Children's Hospital, United States
}

Received: October 21, 2018

Accepted: December 23, 2018

Online Published: December 28, 2018

DOI: $10.5430 /$ jha.v8n1p27

URL: https://doi.org/10.5430/jha.v8n1p27

\begin{abstract}
Nurse retention is of extreme importance in modern healthcare given the ever-increasing nursing shortage and the high cost of training newly hired nurses. Research has repeatedly demonstrated that stress is strongly correlated with nursing staff turnover. This study examines the relationship of Secondary Traumatic Stress, Burnout, Compassion Satisfaction, personal life stress and nurse demographic characteristics with having considered leaving the nursing profession due to work-related stress. A survey was administered to nurses at a large pediatric and women's hospital in the southern United States. Bivariate analyses $(\mathrm{n}=496)$ indicated being Caucasian $(p<.001)$, working fewer hours per week $(p=.009)$, experiencing more personal life stress $(p<.001)$, having higher Burnout $(p<.001)$, or Secondary Traumatic Stress $(p<.001)$ scores or lower Compassion Satisfaction $(p=.015)$ scores were significantly associated with increased likelihood of having considered leaving the nursing profession. In multivariable logistic regression analysis, after variable selection, higher levels of Burnout $(p<.001)$, more life stress $(p=.010)$, being Caucasian $(p<.001)$ and working fewer hours $(p=.004)$ were all significantly associated with higher odds of considering leaving the nursing profession. Interventions to reduce work-related Burnout and help nurses cope with stressful life events are needed to increase retention of nurses in the profession.
\end{abstract}

Key Words: Nurse retention, Burnout, Secondary traumatic stress, Compassion satisfaction

\section{INTRODUCTION}

Based on current trends, some regions of the United States are expected to experience nursing shortages in the near future. ${ }^{[1]}$ Although considerable attention has been applied to nurse retention, shortages do continue. A systematic literature review by Chan et al. ${ }^{[2]}$ concluded that nurses' intention to leave their place of employment and the nursing profession is influenced by complex organizational (work environment, culture, commitment, work demands, and social support) and individual factors (job satisfaction and burnout, with demographic factors showing inconsistent relationships with intention to leave across studies). Han, Trinkoff \& Gurses ${ }^{[3]}$ concluded that nurses with higher job demands, both physical and psychological, longer hours and perceived lower peer/supervisor support and autonomy were more likely to leave.

Gilmartin's review ${ }^{[4]}$ of causal mechanisms to explain why nurses voluntarily leave jobs concluded that individual char-

\footnotetext{
*Correspondence: Joseph Hagan; Email: jlhagan@texaschildrens.org; Address: Room PFW F0720.54, 6651 Main Street, Houston, TX 77030, United States.
}

Published by Sciedu Press 
acteristics affecting psychological reactions to stressors in the workplace have an important influence on decisions to quit. The literature is rife with studies about moral distress, ${ }^{[5]} \mathrm{com}$ passion fatigue $(\mathrm{CF}),{ }^{[6]}$ workplace bullying and violence, ${ }^{[7]}$ negative effects of shiftwork ${ }^{[8]}$ and other issues that nurses face routinely. Sharma et al. ${ }^{[9]}$ identified poor attitudes of physicians, insufficient financial compensation, and heavy workload to be associated with increased professional stress among nurses. Fiabane and colleagues ${ }^{[10]}$ concluded that personal (including mental and physical health) and organizational (workload, control, rewards) factors are significantly associated with work engagement. Finally, nurses have lives outside of their jobs that may also influence their decision to remain in a job or even in the profession of nursing. ${ }^{[11]}$

While previous studies have firmly established a relationship between nurse stress and turnover, the body of literature examining the relationship between different kinds of employment-related and life-related stress on intention to leave the adult nursing profession remains incomplete, ${ }^{[12]}$ and even sparse in pediatric nursing. The purpose of this study was to examine the relationship of work related stress, as measured by Secondary Traumatic Stress (STS), Burnout (BO), Compassion Satisfaction (CS), as well as personal life stressors and nurse demographic characteristics with having considered leaving the nursing profession due to workrelated stress.

\section{Methods}

The study was conducted at a large academic quaternary care pediatric and women's hospital in the southern United States. The current study was a secondary analysis of data originally obtained to assess presence of compassion fatigue among nurses employed at the hospital. ${ }^{[13]}$ The survey was comprised of the Professional Quality of Life Scale (ProQOL) Version $5^{[14]}$ and the Social Readjustment Rating Scale (SRRS), ${ }^{[15]}$ additional demographic questions and a question about whether or not the respondent has considered leaving the nursing profession due to work-related stress. After receiving approval from the Institutional Review Board, a SurveyMonkey link was distributed via an email tree through nursing leaders. In order be included in the study, respondents had to report that they provide direct patient care or are responsible for nurses who provide direct patient care.

\subsection{Instruments}

The ProQOL consists of the following three subscales: STS, $\mathrm{BO}$, and CS. CS measures the positive aspect of the nurse's professional quality of life as a helper; BO is characterized by emotions such as anger, frustration, depression and exhaustion; STS manifests as fear and occupational stress. ${ }^{[14]}$
Stamm ${ }^{[14]}$ conceptualizes compassion fatigue as a combination of high BO and STS. Likert scale responses to the ProQOL items were used to compute subscale scores as described by Stamm (2010, p 15-16). Cronbach's alpha was used to assess the reliability of the three ProQOL subscales. The SRRS ${ }^{[15]}$ measures personal life stress by assigning numerical weights to life changing events that have occurred in the past 12 months. Stamm ${ }^{[14]}$ reports $\alpha=0.88$ for CS, $\alpha=$ 0.81 for STS and $\alpha=0.75$ for BO.

\subsection{Data analysis}

Relationships of the three ProQOL subscale scores, SRRS scores and nurse employment and demographic characteristics with having considered leaving the nursing profession due to work-related stress were investigated. Initially, logistic regression analysis was used to examine each individual independent variable's bivariate association with having considered leaving the nursing profession due to work-related stress. A multivariable logistic regression model followed to include all variables exhibiting a significant bivariate association. Backward variable selection was used to arrive at the final regression model for which all predictors were significantly associated with having considered leaving the nursing profession due to work-related stress. The HosmerLemeshow goodness-of-fit test was used to check the regression model for lack of fit. SAS version 9.4 (SAS Institute Inc., Cary, North Carolina) was used for all data analysis.

Using the method for sample size estimation due to Hsieh, ${ }^{[16]}$ the 496 study subjects provided $81 \%$ statistical power to detect $(\alpha=0.05)$ a true odds ratio of 1.33 for the bivariate association of a normally distributed independent variable with having considered leaving the nursing profession due to work related stress, when comparing the value of the independent variable one standard deviation above the mean to the reference point mean.

\section{RESUlTS}

The human resources department estimated that there were 3,300 nurses employed at the hospital when the survey was administered. A total of 864 participants took at least some of the survey, with only 496 responding to all ProQOL and SRRS items. These 496 participants' data were analyzed for the current study, yielding a response rate of $496 / 3,300=15 \%$.

The majority of subjects were female (98\%) and Caucasian (58\%) with an average age of 40.3 years (see Table 1 ). One hundred seventy-nine (36\%) of the 496 of respondents indicated that they had considered leaving the nursing profession due to work-related stress. Using the guidelines for interpreting Chronbach's alpha provided by DeVellis, ${ }^{[17]}$ the CS ( $\alpha=$ $0.72)$ and STS $(\alpha=0.77)$ subscales of the ProQOL demon- 
strated "acceptable" reliability while the internal consistency of the BO subscale $(\alpha=0.53)$ was "poor".

Table 1. Respondent characteristics

\begin{tabular}{|c|c|}
\hline Characteristic & Frequency $^{\dagger}(\%)$ \\
\hline \multicolumn{2}{|l|}{ Gender $(n=488)$} \\
\hline - Female & $478(98)$ \\
\hline - Male & $10(2)$ \\
\hline \multicolumn{2}{|l|}{ Race $(n=493)$} \\
\hline - African American & $50(10)$ \\
\hline - Asian & $86(17)$ \\
\hline - Caucasian & $285(58)$ \\
\hline - Hispanic/Latino & $58(12)$ \\
\hline - Other & $14(3)$ \\
\hline \multicolumn{2}{|l|}{ Education level $(n=495)$} \\
\hline - Certificate & $4(1)$ \\
\hline - Diploma & $11(2)$ \\
\hline - Associate's degree & $72(15)$ \\
\hline - Bachelor's degree & $335(68)$ \\
\hline - Master's degree & $65(13)$ \\
\hline - Post-master's degree & $4(1)$ \\
\hline - Doctorate & $4(1)$ \\
\hline \multicolumn{2}{|l|}{ Patient care setting $(n=494)$} \\
\hline - Inpatient & 379 (77) \\
\hline - Outpatient & $115(23)$ \\
\hline \multicolumn{2}{|l|}{ Typical work shift $(n=490)$} \\
\hline - Days & $326(67)$ \\
\hline - Nights & $150(31)$ \\
\hline - Combination & $14(3)$ \\
\hline \multicolumn{2}{|l|}{ Certified in specialty area $(n=491)$} \\
\hline - Yes & $232(47)$ \\
\hline - No & $259(53)$ \\
\hline \multicolumn{2}{|c|}{$\begin{array}{l}\text { Considered leaving the nursing profession due to } \\
\text { work-related stress }(n=496)\end{array}$} \\
\hline - Yes & $179(36)$ \\
\hline - No & $317(64)$ \\
\hline Characteristic & Mean $\pm S D$ (range) \\
\hline - Age in years $(n=487)$ & $40.3 \pm 11.6(22-67)$ \\
\hline $\begin{array}{l}\text { - Years practicing as a nurse } \\
(\mathrm{n}=477)\end{array}$ & $13.8 \pm 10.7(0-46)$ \\
\hline $\begin{array}{l}\text { - Hours worked in a typical week } \\
(\mathrm{n}=495)\end{array}$ & $38.1 \pm 8.9(3-84)$ \\
\hline $\begin{array}{l}\text { - Social Readjustment Rating Scale } \\
\text { score }(\mathrm{n}=496)\end{array}$ & $136.4 \pm 96.0(0-482)$ \\
\hline $\begin{array}{l}\text { - ProQOL Compassion Satisfaction } \\
\text { score }(\mathrm{n}=496)\end{array}$ & $33.8 \pm 7.0(20-50)$ \\
\hline - ProQOL Burnout score $(\mathrm{n}=496)$ & $28.4 \pm 5.5(12-41)$ \\
\hline $\begin{array}{l}\text { - ProQOL Secondary Traumatic } \\
\text { Stress score }(\mathrm{n}=496)\end{array}$ & $27.4 \pm 6.4(11-43)$ \\
\hline
\end{tabular}

Bivariate analyses indicated being Caucasian $(p<.001)$, working fewer hours per week $(p=.009)$, experiencing more personal life stress $(p<.001)$, higher ProQOL BO $(p<.001)$, or STS $(p<.001)$ scores or lower CS $(p=.015)$ scores was significantly associated with increased likelihood of having considered leaving the nursing profession (see Table 2). After backward variable selection, only Caucasian race $(p<.001)$, number of hours worked in a typical week $(p=.004)$, personal life related stress $(p=.010)$ and BO $(p<.001)$ were significantly related to having considered leaving the nursing profession due to work-related stress. Specifically, Caucasian nurses had more than double the odds of having considered leaving the nursing profession due to work related stress compared to other races after controlling for the other variables in the regression model (adjusted odds ratio 2.037 , 95\% confidence interval: $1.359-3.054)$. After controlling for the other variables in the model, each additional hour worked per week decreased the odds of having considered leaving the profession due to work-related stress by $3.4 \%$ (adjusted odds ratio $0.966,95 \%$ confidence interval: 0.943-0.989), while every point increase in the ProQOL BO scale increased the odds by $8.8 \%$ (adjusted odds ratio 1.088 , 95\% confidence interval: $1.046-1.131$ ) and every point increase in the SRRS increased the odds by $0.3 \%$ (adjusted odds ratio $1.003,95 \%$ confidence interval: 1.001-1.005). The logistic regression model as a whole contributed significantly to the prediction of having considered leaving the profession due to work-related stress $(p<.001)$. This regression model did not exhibit significant lack of fit $(p=.602)$ so the results can be considered to be valid.

\section{Discussion}

In a multivariable analysis to adjust for potential confounders, we found that higher levels of $\mathrm{BO}$, more life stress, being Caucasian and working fewer hours were all associated with significantly higher odds of considering leaving the nursing profession. Higher levels of BO manifest as frequently feeling trapped in the job as a nurse, worn out by work as a nurse, overwhelmed by the work load, bogged down by the system and losing sleep due to being traumatized by patients' experiences. On the other hand, BO levels are reduced by frequently feeling that you are a caring person, you are the person you always wanted to be, feeling connected to others, being happy to have chosen this work, and having beliefs that sustain you. ${ }^{[14]}$

Respondents were asked if they had any comments based on their personal experiences as a nurse. Many mentioned that they became a nurse because they are a caring person who enjoys helping people. Many also remarked that stress from job frequently spills over into their personal life and even affecting physical health. Several comments described specific plans to leave the nursing profession to pursue another career. 
In contrast, one nurse remarked, "I have often contemplated leaving the nursing profession but stay because I do consider it a calling that I could not leave without regret. Someone needs to do this work, and I want it to be someone who cares. It might as well be me."

Table 2. Comparison of respondents who have versus have not considered leaving the nursing profession due to work-related stress

\begin{tabular}{|c|c|c|c|}
\hline \multirow[b]{2}{*}{ Characteristic } & \multicolumn{2}{|c|}{$\operatorname{Proportion}^{\dagger}(\%)$} & \multirow[b]{2}{*}{$p$-value } \\
\hline & $\begin{array}{l}\text { Have not Considered Leaving Due to } \\
\text { Work-Related Stress }(n=317)\end{array}$ & $\begin{array}{l}\text { Considered Leaving Due to } \\
\text { Work-Related Stress }(n=179)\end{array}$ & \\
\hline Female & $304 / 313(97)$ & $174 / 175(99)$ & .121 \\
\hline Caucasian & $162 / 317(51)$ & $123 / 179(69)$ & $<.001^{*}$ \\
\hline Bachelor's degree or higher & $263 / 317(83)$ & $145 / 179(81)$ & 625 \\
\hline Inpatient care setting & $241 / 316(76)$ & $138 / 178(78)$ & .750 \\
\hline Day shift & 203/317 (64) & $123 / 179(69)$ & .320 \\
\hline Certified in specialty area & $153 / 316(48)$ & $79 / 175(45)$ & .486 \\
\hline \multirow[b]{2}{*}{ Characteristic } & \multicolumn{2}{|c|}{ Mean $\pm S D$} & \\
\hline & $\begin{array}{l}\text { Considered Leaving Due to } \\
\text { Work-Related Stress ( } \mathrm{n}=179)\end{array}$ & $\begin{array}{l}\text { Have not Considered Leaving Due } \\
\text { to Work-Related Stress }(\mathrm{n}=\mathbf{3 1 7})\end{array}$ & $p$-value \\
\hline Age in years & $(\mathrm{n}=177) 39.8 \pm 10.9$ & $(\mathrm{n}=310) 40.6 \pm 12.0$ & .526 \\
\hline Years practicing as a nurse & $(\mathrm{n}=174) 13.1 \pm 9.4$ & $(\mathrm{n}=303) 14.2 \pm 11.4$ & .317 \\
\hline Hours worked in a typical week & $(\mathrm{n}=179) 36.6 \pm 8.9$ & $(\mathrm{n}=316) 38.9 \pm 8.8$ & $.009^{*}$ \\
\hline Social Readjustment Rating Scale score & $(\mathrm{n}=179) 156.8 \pm 96.4$ & $(\mathrm{n}=317) 124.9 \pm 93.9$ & $<.001^{*}$ \\
\hline ProQOL Compassion Satisfaction score & $(\mathrm{n}=179) 32.8 \pm 5.7$ & $(\mathrm{n}=317) 34.4 \pm 7.5$ & $.015^{*}$ \\
\hline ProQOL Burnout score & $(\mathrm{n}=179) 30.1 \pm 4.9$ & $(\mathrm{n}=317) 27.5 \pm 5.6$ & $<.001^{*}$ \\
\hline ProQOL Secondary Traumatic Stress score & $(n=179) 28.8 \pm 6.3$ & $(n=317) 26.7 \pm 6.4$ & $<.001^{*}$ \\
\hline
\end{tabular}

Note. ${ }^{\dagger}$ Sample sizes are not the same for each characteristic because a different number of responses were missing; ${ }^{*}$ Indicates a statistically significant association with having considered leaving the nursing profession due to work-related stress

Historically, published research has repeatedly shown that higher levels of job stress are associated with nurse attrition. ${ }^{[18-22]}$ Consistent with our findings, a systematic review of systematic reviews about turnover determinants identified stress and burnout, lower job satisfaction and commitment as strong determinants of job turnover. ${ }^{[12]}$ In a qualitative study, Happell et al. ${ }^{[23]}$ identified the following as specific sources of occupational stress among nurses: a high workload, lack of physician availability, management not being supportive, problems with the human resources department, co-worker conflict and communication issues, demands of patients' relatives, working night shift, parking frustrations, patient handoff procedures and lack of a dedicated break area. And looking beyond workplace factors, Viotti and Converso $^{[11]}$ identified that increased negative qualitative and quantitative contexts have significant influence on healthcare worker behavior outside of work. Stacciarini and Troccoli ${ }^{[24]}$ found measures of general psychological and physical health to be significantly correlated with nurses' job satisfaction. This could explain the significant association observed in the current study between personal life stress and having considered leaving the nursing profession. Although it may appear intuitive, we are aware of no previous nursing study having demonstrated a relationship between stress due to life changing events and intention to leave the nursing profession. As one respondent said, "All of your efforts and emotions should be directed at your patients when you are at work, and inversely then directed at yourself to heal from this exhausting care - however life adds many other factors into this equation daily and it becomes difficult to manage." Other respondents described specific stressful events in their personal life that compromised their ability to do their job as a nurse. It would seem that our minds cannot easily compartmentalize the source of stress, so a stressful personal life could sensitize a nurse to feeling compelled to leave the profession due to additional stress experienced in the work place.

Regarding the inverse association between the number of hours worked per week and having considered leaving the profession, it seems reasonable that nurses who are so dissatisfied with their job that they are considering leaving the 
profession would choose to work fewer hours. For many participants, the reduced hours working as a nurse could be the manifestation of a decreased commitment to nursing, perhaps because working as a nurse is not the top priority due to other competing interests such as another job or family life. Also some nurses who live in households with a high income irrespective of the nursing salary would surely reduce the number of hours worked since the financial pressure to work more is not present.

We can only speculate about the association of race with having considered leaving the nursing profession. In the context of research, race is often confounded with other socioeconomic indicators, ${ }^{[25]}$ so perhaps these other factors, instead of race, are causally related to considering leaving the profession. Perhaps Caucasian nurses' household incomes are higher on average so continuing to work as a nurse is not always necessary.

Leveck and Jones ${ }^{[26]}$ reported that "Demographic and work experience variables influenced intention to leave and turnover through the effects of felt stress, job satisfaction, and organizational commitment." In fact, in contrast to the current study, a number of other studies have found that years of nursing experience was inversely correlated with intention to leave. ${ }^{[18,19,27,28]}$ At the institution where this study was conducted, human resources data indicates that nurses are much more likely to leave within the first 6 months of being hired. So it is interesting that there was no association found in this study between years of nursing experience and intention to leave the nursing profession due to work-related stress. It could be that the newer nurses who leave the institution are merely moving to other health care facilitates. But previous research suggests that the stress of transitioning into a nursing career can be a reason for leaving the profession. ${ }^{[29-31]}$ When considering interventions to prevent the loss of new nurses, Trepanier et al. ${ }^{[32]}$ estimated that having a new graduate nurse residency program would decrease the 12-month turnover rate 6\%-36\%, reduce contract labor costs $\$ 5,490-\$ 19,099$ per average daily census and yield a net savings of $\$ 10-\$ 50$ per patient day compared to traditional orientation methods.

As mentioned above, and a point brought up in a number of nurses' open-ended comments, conflict with physicians can be a substantial source of stress among nurses. Several studies ${ }^{[9,33,34]}$ have found that more senior nurses are better able to handle conflict with physicians which results in their experiencing less stress. So it would seem that teaching less experienced nurses strategies to effectively deal with conflict with physicians could be beneficial. Along these lines, a recent systematic review ${ }^{[12]}$ found evidence for effectiveness

Published by Sciedu Press of only two interventions to increase nurse retention: 1) preceptorships for new graduates and 2) leadership for group cohesion. Both of these interventions should help to mitigate the adverse effects of work-related stress on relatively inexperienced nurses.

The costs associated with nurse attrition can be very high. ${ }^{[35]}$ Thus any interventions that can prevent nurses from leaving would be very beneficial to the institution. Given the established links between nurse stress, BO and turnover, targeted interventions to mitigate the harms of $\mathrm{BO}$ and life stress should be considered. A surprisingly simple change like recognizing nurses' performance has been shown to reduce the effects of job stress and increase intention to stay. ${ }^{[36]}$ Any effective method for reducing $\mathrm{BO}$ and helping nurses to cope with stress should be welcomed. A meta-analysis of 31 studies involving 14,567 nurses concluded that decreased job stress was the best predictor of job satisfaction. ${ }^{[37]}$ Potter et al. ${ }^{[38]}$ implemented a five week CF resiliency program that significantly reduced ProQOL STS scores among oncology nurses.

Management leadership style has been shown to be directly related to nurse retention. ${ }^{[26,27]}$ The importance of supportive leadership was also commented upon in numerous openended responses. For example, one participant said, "I think inherently the work that we do is taxing and exhausting but so very rewarding. However, unfortunately, I learned that the reward can be overshadowed by this exhaustion when you add the burdens of nonsupportive leadership. Feeling supported and receiving the necessary tools to flourish and not flounder in your role as a nurse is imperative to maintaining that work/life balance." It would seem that training nurse managers to be more supportive and complimentary toward their staff would improve nurse morale and, as a result, increase retention.

\section{Limitations of the study}

This study is not without limitations. The response rate was lower than desired, but realistically not lower than expected given the length of the survey. Efforts were made to increase participation by giving short presentations about the study at various nursing shared governance meetings and posting flyers advertising the study in non-patient areas. Additionally, an email reminder encouraging participation was sent one week after the initial survey invitation. However, nurse leaders at the institution have remarked that most institutional emails are not read by a large proportion of the nurses. Further research is needed to determine if the findings generalize to nurses employed at other institutions given the low response rate and unique setting of this study. The poor internal consistency of the ProQOL BO subscale might also 
be of concern, although a study of 221 critical care nurses ${ }^{[39]}$ observed an even lower reliability for this subscale $(\alpha=$ $0.45)$.

\section{Conclusions}

The purpose of this study was to examine the relationship of STS, BO, CS, personal life stress and nurse demographic characteristics with having considered leaving the nursing profession due to work-related stress. No other published study has examined the association of the three ProQOL subscales and the SRRS with nurses' intention to leave the profession. Our finding that stress due to recent life changing events correlates with increased incidence of intention to leave the nursing profession is novel. Based on the findings of this study, healthcare organizations can create assessments to identify nurses who are at risk for leaving the profession due to work-related stress. Then counseling and interventions can be implemented to help such nurses cope with life stress and develop strategies to reduce symptoms of $\mathrm{BO}$. Fu- ture research is warranted with regard to helping nurses to cope with stress, both job related and general life stress, and studying the impact of such interventions on nurse retention. Such research is necessary in modern times when employers are realizing that taking a holistic and proactive approach to nursing employees' health will improve retention.

\section{ACKNOWLEDGEMENTS}

The authors would like to thank Dr. Marlene Walden, Dr. Barbara McFadden, Pamela Krinock, Aaron Loeb, Lindsay Stephens and Darlene Acorda for their invaluable participation in the original study.

\section{STUDY APPROVAL}

The study (protocol H-36167) was approved by the Baylor College of Medicine Institutional Review Board on January 28, 2015.

\section{CONFlicts of InTERest Disclosure}

The authors declare they have no conflicts of interest.

\section{REFERENCES}

[1] Auerbach DI, Buerhaus PI, Staiger DO. How fast will the registered nurse workforce grow through 2030? Projections in nine regions of the country. Nursing Outlook. 2017; 65(1): 116-122. PMid: 27502764. https://doi.org/10.1016/j.outlook. 20 16.07 .004

[2] Chan ZCY, Tam WS, Lung MKY, et al. A systematic review of nurse shortage and the intention to leave. Journal of Nursing Management. 2013; 21: 605-613. PMid: 23406374. https ://doi .org/10.111 $1 / j .1365-2834.2012 .01437 . x$

[3] Han K, Trinkoff AM, Gurses AP. Work-related factors, job satisfaction and intent to leave the current job among United States nurses. Journal of Clinical Nursing. 2015; 24: 3224-3232. PMid: 26417730. https://doi.org/10.1111/jocn. 12987

[4] Gilmartin MJ. Thirty years of nursing turnover research: Looking back to move forward. Medical Care Research and Review. 2013; 70(1): 3-28. PMid: 22679280. https ://doi .org/10.1177/1077 558712449056

[5] McAndrew NS, Leske J, Schroeter K. Moral distress in critical care nursing: The state of science. Nursing Ethics. 2016; 25(5): 552 570. PMid: 27660185. https://doi.org/10.1177/09697330 16664975

[6] Sinclair S, Raffin-Bouchal S, Venturato L, et al. Compassion fatigue: A meta-narrative review of the healthcare literature. International Journal of Nursing Studies. 2017; 69: 9-24. PMid: 28119163. https://doi.org/10.1016/j.ijnurstu.2017.01.003

[7] Philips JP. Workplace violence against health care workers in the United States. New England Journal of Medicine. 2016; 374: 16611669. PMid: 27119238. https ://doi.org/10.1056/NEJMra15 01998

[8] Matheson A, O'Brien L, Reid JA. The impact of shiftwork on health: A literature review. Journal of Clinical Nursing. 2014; 23(23-24):
3309-3320. PMid: 24460821. https://doi.org/10.1111/jocn .12524

[9] Sharma M, Rush SE. Mindfulness-based stress reduction as a stress management intervention for healthy individuals: A systematic review. Journal of Evidence-Based Complimentary \& Alternative Medicine. 2014; 19(4): 271-286. PMid: 25053754. https://doi. org/10.1177/2156587214543143

[10] Fiabane E, Giorgi I, Argentero P. Work engagement and occupational stress in nurses and other healthcare workers: The role of organizational and personal factors. Journal of Clinical Nursing. 2013; 22(17-18): 2614-2624. PMid: 23551268. https ://doi .org/10.1 $111 /$ jocn .12084

[11] Viotti S, Converso D. Relationship between job demands and psychological outcomes among nurses: Does skill discretion matter? Journal of Occupational Medicine and Environmental Health. 2016; 29(3): 439-460. PMid: 26988883. https://doi.org/10.13075 /ijomeh. 1896.00520

[12] Halter M, Boiko O, Ferruccio P, et al. The determinants and consequences of adult nursing staff turnover: a systematic review of systematic reviews. BMC Health Services Research. 2017; 17: 824. PMid: 29246221. https://doi.org/10.1186/s12913-017-2707-0

[13] Acorda D, Stephens L. Compassion fatigue assessment of nurses in a large academic pediatric and women's health care system. Society of Pediatric Nurses 26th Annual Conference. Minneapolis, Minnesota. April 21-24, 2016.

[14] Stamm BH. The Concise ProQOL Manual, 2nd ed. Pocatello, ID: ProQOL. Org.; 2010.

[15] Holmes TH, Raye RH. The social readjustment rating scale. Journal of Psychosomatic Research. 1967; 11(2): 213-221. https: //doi.org/10.1016/0022-3999(67)90010-4

[16] Hsieh FY. Sample size tables for logistic regression. Statistics in Medicine. 1989; 8: 795-802. PMid: 2772439. https ://doi.org/ $10.1002 / \mathrm{sim} .4780080704$ 
[17] DeVellis RF. Scale development: Theory and applications. Los Angeles: Sage; 2012. 109-110 p.

[18] Applebaum, Fowler S, Fiedler N, et al. The impact of environmental factors on stress, job satisfaction and turnover intention. Journal of Nursing Administration. 2010; 40: 323-328. PMid: 20661062. https://doi.org/10.1097/NNA.0b013e3181e9393b

[19] Hayes LJ, O'Brien-Pallas L, Duffield C, et al. Nursing turnover: A literature review. International Journal of Nursing Studies. 2006; 43: 237-263. PMid: 15878771. https://doi.org/10.1016/j.ijnu rstu.2005.02.007

[20] Wright TA, Bonnet DG. The moderating effects of employee tenure on the relation between organizational commitment and job performance: A meta-analysis. Journal of Applied Psychology. 2002; 87: 1183-1190. https://doi.org/10.1037/0021-9010.87.6.118 3

[21] Mitchell TR, Holtom BC, Lee TW, et al. Why people stay: Using job embeddedness to predict voluntary turnover. Academy of Management Journal. 2001; 44: 1102-1121.

[22] Tai TWC, Bame SI, Robinson CD. Nursing turnover research, 19771996. Social Science \& Medicine. 1998; 7: 1905-1924. https: //doi.org/10.1016/S0277-9536(98)00333-5

[23] Happell B, Dwyer T, Reid-Searl K, et al. Nurses and stress: recognizing causes and seeking solutions. Journal of Nursing Management. 2013; 21: 638-647. PMid: 23700980. https://doi.org/10.111 $1 /$ jonm. 12037

[24] Stacciarini JM, Troccoli BT. Occupational stress and constructive thinking: Health and job satisfaction. Journal of Advanced Nursing. 2004; 46(5): 480-487. PMid: 15139936. https://doi.org/10.1 $111 / j .1365-2648.2004 .03022 \cdot \mathrm{x}$

[25] Kaufman JS, Cooper RS. McGee DL. Socioeconomic Status and Health in Blacks and Whites: The Problem of Residual Confounding and the Resiliency of Race. Epidemiology. 1997; 8(6): 621-628. https://doi.org/10.1097/00001648-199710000-00002

[26] Leveck ML, Jones CB. The nursing practice environment, staff retention, and quality of care. Research in Nursing and Health. 1996; 19: 331-343. https://doi.org/10.1002/(SICI) 1098-2 40X (199608) $19: 4<331$ : : AID-NUR7>3.0.CO; $2-\mathrm{J}$

[27] Blake N, Leach LS, Robbins W, et al. Healthy work environments and staff nurse retention: The relationship between communication, collaboration, and leadership in the pediatric intensive care unit. Nursing Administration Quarterly. 2013; 37(4): 356-370. PMid: 24022290. https://doi.org/10.1097/NAQ.0b013e3182a2fa47
[28] Wagner CM. Predicting nursing turnover with catastrophe theory. Journal of Advanced Nursing. 2011; 66: 2071-2084. http://dx.d oi .org/10.4103/1119-3077.104529

[29] Nei D, Snyder LA, Litwiller BJ. Promoting retention of nurses: A meta-analytic examination of causes of nurse turnover. Healthcare Management Review. 2015; 40(3): 237-253. PMid: 24901298. https://doi.org/10.1097/HMR.0000000000000025

[30] Scott ES, Keehner Engelke M, Swanson M. New graduate nurse transitioning: Necessary or nice? Applied Nursing Research. 2008; 21(2): 75-83. PMid: 18457746. https://doi.org/10.1016/j. apnr.2006.12.002

[31] Lavoie-Tremblay M, Leclerc E, Marchionni C, et al. The needs and expectations of generation $\mathrm{Y}$ nurses in the workplace. Journal for Nurses in Staff Development. 2010; 26(1): 2-8. PMid: 20098166. https://doi.org/10.1097/NND.0b013e3181a68951

[32] Trepanier S, Early S, Ulrich B, et al. New graduate nurse residency program: A cost-benefit analysis based on turnover and contract labor usage. Nursing Economics. 2012; 30(4): 207-214. PMid: 22970551.

[33] French SE, Lenton RL, Walters V, et al. An empirical evaluation of an expanded nursing stress scale. Journal of Nursing Measurement. 2000; 8(2): 161-178. PMid: 11227582. https://doi.org/10.1 891/1061-3749.8.2.161

[34] Tabak N, Orit K. Relationship between how nurses resolve their conflicts with doctors, their stress and job satisfaction. Journal of Nursing Management. 2007; 15(3): 321-331. PMid: 17359432 https://doi.org/10.1111/j.1365-2834.2007.00665.x

[35] Li Y, Jones CB. A literature review of nursing turnover costs. Journal of Nursing Management. 2013; 21: 405-418. PMid: 23406301. https://doi.org/10.1111/j.1365-2834.2012.01411.x

[36] Abualrub RF, Al-Zarui M. Job stress, recognition, job performance and intention to stay at work among Jordanian hospital nurses. Journal of Nursing Management. 2008; 16: 227-236. PMid: 18324981. https://doi.org/10.1111/j.1365-2834.2007.00810.x

[37] Zangaro GA, Soeken KL. A meta-analysis of studies of nurses' job satisfaction. Research in Nursing \& Health. 2007; 30: 445-458. PMid: 17654483. https://doi.org/10.1002/nur. 20202

[38] Potter P, Deshield T, Berger JA, et al. Evaluation of a compassion fatigue resiliency program for oncology nurses. Oncology Nursing Forum. 2013; 40(2): 180-187. PMid: 23448743. https : //doi.org/10.1188/13. ONF.180-187

[39] Sacco TL, Ciurzynski SM, Harvey ME, et al. Compassion satisfaction and compassion fatigue among critical care nurses. Critical Care Nursing. 2015; 35(4): 32-42. PMid: 26232800. https : //doi.org/10.4037/ccn2015392 